Textos 



\title{
A vacina da Aids, a quimera e a vaca gorda
}

JOSÉ DA ROCHA CARVALHEIRO

\author{
Uma conquista \\ da humanidade
}

$\mathrm{O}$

ATUAL PRESIDENTE dos EUA declara enfaticamente que vai derrotar a Aids.

Lança um desafio, a si próprio e aos cientistas do seu país, de conseguir uma vacina eficaz. Será a primeira conquista científica relevante do século XXI. No passado, o presidente Kennedy prometeu colocar um homem na lua "nos próximos dez anos", e cumpriu a promessa antes que se esgotasse o prazo. Desde então, a humanidade tem certeza de que a Casa Branca não brinca com essas coisas. No presente, outra conquista importante no campo da exploração do universo: os EUA conseguiram a proeza de colocar uma sonda em solo marciano. O sucesso foi tão grande que, além da sonda, receberam carinhosos nomes próprios o veículo explorador e as pedras do seu caminho, apelidadas em homenagem a personagens de histórias em quadrinhos.

Esse aparente à vontade traduz, antes de mais nada, o hábito arraigado de convivência com o sucesso, por mais formidável que este seja. É o que também se espera no caso da Aids, embora a situação seja bem mais complexa. Além do indispensável desenvolvimento científico e tecnológico, existem questões de natureza econômica, social e ética que não podem ser ignoradas. Espera-se que o atual presidente, instruído por sua competente assessoria, consiga concretizar sua louvável iniciativa. Na reunião de cúpula dos países ricos, G-7, na verdade composto por oito países com a inclusão da Rússia, em Denver, no Colorado, o presidente Clinton fez incluir o mesmo compromisso na declaração final. Já existe um movimento para envolver os países pobres, G-77, na realidade composto por mais de uma centena de países, no mesmo esforço. Circula, colhendo assinaturas institucionais (inclusive de ONGs), um International call for action on HIV vaccine development (Iavi Report, 1997a).

As conquistas da humanidade no terreno do controle das doenças têm múltiplas determinações. A efetividade das ações não exige necessariamente um conhecimento preciso da intimidade do processo que se quer conter: a propagação da doença no meio social. A história da medicina está repleta de exemplos. A Organização Pan-Americana de Saúde (Opas) publicou um extenso volume, o Desafio da epidemiologia (Buck et al., 1988). Contém, na íntegra ou resumidos, quase 100 tra- 
balhos publicados, do século XVIII até nossos dias, considerados essenciais para o conhecimento da evolução do pensamento epidemiológico. Comentados em debate transcrito na íntegra no livro, os trabalhos são agrupados em capítulos que refletem essa evolução. No desenvolvimento histórico há um salto, desde Hipócrates, no século V a.C., até meados do século XVIII. Neste século, selecionaram-se quatro publicações. Uma delas é de Edward Jenner, inglês considerado pai, ou precursor, da vacinação.

A discussão, travada pelos autores da coletânea, discorre sobre a maneira contraditória como raciocínios equivocados conduziram a linhas de atuação e pesquisa que terminaram por provar sua eficácia no controle de doenças. No caso específico de Jenner, decidiram incluir apenas o trabalho em que observa a raridade da varíola (smallpox) entre as ordenhadoras de vacas. Estas eram vítimas freqüentes de uma doença profissional adquirida pelo contato das mãos com pústulas dos úberes das vacas, conhecida como cowpox (varíola bovina). Passados praticamente dois séculos, é interessante recordar a oposição da Igreja, na época, à proposta de Jenner: inocular homens e mulheres com o material purulento do cowpox, para protegê-los contra a varíola (smallpox). Não se considerava um ato cristão a introdução de produto animal no corpo humano. A prática então aceita, a variolação, originária da China, consistia em inocular o produto das pústulas da varíola (humana) nas pessoas que queriam se proteger. O fato é que Jenner, tentando provar sua idéia, fez um experimento com um único sujeito, um menino. Comentário jocoso de um dos autores da coletânea: "Evitou o problema de aleatorização".

\section{As vacinas e a teoria do germe}

Um século após as experiências de Jenner com a varíola bovina, coube a Louis Pasteur, católico fervoroso, tomar o centro do palco. A história de vida, que se esconde por detrás da lenda, é magnificamente analisada por Lambrichs (1993) em um precioso texto em que põe em tela de juízo a "verdade médica". A maneira contraditória como este "sábio, herói e benfeitor da humanidade" se comportava antecipou de um século a controvérsia sobre a autoria da descoberta da associação do vírus HIV com a Aids. Pasteur, ao apresentar suas idéias geralmente brilhantes, jamais fazia menção às fontes. Muito menos atribuía créditos aos precursores. Esta característica mereceu de Lambrichs (1993) a observação cáustica: "Como admitir que apresente suas descobertas quase como criadas do nada (ex nibilo nibil), o mesmo cientista que demonstrou a impossibilidade da geração espontânea?”. O caso específico do sucesso com a vacina anti-rábica, aplicada no menino Joseph Meister sem estar ainda "no ponto" (opinião de Roux, colaborador de Pasteur), dá bem uma idéia da ousadia do brilhante cientista, notável por sua intuição. Comentando esta verdadeira obsessão de Pasteur por agir rapidamente, Lambrichs (1993) relata acontecimentos anteriores e escreve: "Não foi a primeira vez que ele se atirou à água antes de aprender a nadar direito".

$\mathrm{Na}$ verdade, estava-se conformando, a partir de meados do século XIX, a teoria do germe, que segue vigindo como paradigma científico na área médica. A 
cada doença corresponderia um germe. A consolidação da microbiologia como disciplina científica, e seu desdobramento natural (a imunologia), devem muito à ousadia de Pasteur. O episódio do menino mordido, os apelos da família, o salto de Pasteur na água "sem saber nadar", são emblemáticos desse período. Desdobramse até hoje as idéias centrais da teoria do germe, e seus complementos. De um lado, a da transmissão por insetos, motivo de intensa controvérsia em diversos campos; em passado recente, chegou a ser pensada no início da epidemia de HIV/Aids. De outro, a promessa de proteção, difundida pelo trabalho dos prógonos da imunologia: cada doença, um micróbio; cada micróbio, uma vacina.

\section{Significados, representações \\ e mitos: a emergência do controle social}

É curioso como essas idéias nos alcançam. A caça ao "vírus do câncer", desejo perene de cientistas e leigos, traz implícito seu corolário: um vírus; portanto, uma vacina. O desenvolvimento da moderna biologia molecular, com impacto importante no campo do conhecimento sobre HIV/Aids, tem muito de revitalização da teoria do germe. Da busca incessante por preservar o paradigma pasteuriano, a chamada medicina científica. A emergência das ciências sociais e das ciências do comportamento na saúde pública, a contextura do conceito epidemiológico de risco, o debate sobre a diferença entre práticas individuais e estilo de vida, a vulnerabilidade e, em particular, a fragilidade (frailty), tendem todos a um questionamento do paradigma hegemônico sem, no entanto, um mergulho no sombrio passado da teoria miasmática.

Nesse contexto de extrema complexidade vêm somar-se, contraditoriamente, a globalização da economia e o avassalador crescimento do controle social com sua exigência de comportamento ético na área da saúde. A revolução da biotecnologia fez ressurgir o interesse das grandes empresas farmacêuticas pelas vacinas (Gadelha, 1996). A oligopolização da produção industrial na área é marcante, conduzindo a disputas por patentes e discussões ásperas quanto à propriedade intelectual. $\mathrm{O}$ aparecimento das drogas órfãs é apenas um exemplo de desenvolvimento industrial num mundo globalizado. Desde há muito a descoberta de fármacos, e sua introdução no comércio pela indústria farmacêutica, deixou de ser uma obra do acaso. A bioquímica e a química fina, além da fisiologia, a farmacologia e outras disciplinas biomédicas, desempenham papel saliente nesse desenvolvimento das ciências duras (hard sciences) da área da saúde. A biotecnologia fez com que o mesmo requinte do desenvolvimento científico e tecnológico dos fármacos ingressasse no campo da produção de vacinas. Buscam-se vacinas mais eficazes, com menos riscos de reações adversas, mais estáveis às variações térmicas, imunogênicas em doses menores e, de preferência, aplicadas em injeção única. Acontece, freqüentemente, a um laboratório de pesquisa de uma grande empresa farmacêutica dar com alguma mudança em um radical de uma molécula de fármaco que o transforma em agente ativo contra alguma doença exclusiva do mundo subdesenvolvido. A nova droga, assim descoberta, está fadada a aumentar a lista das drogas órfãs. 
A indústria farmacêutica dos países desenvolvidos atua com desenvoltura. Congressos, seminários e workshopssão freqüentes para tratar do tema. Um Simpósio internacional sobre desenvolvimento e utilização de vacinas foi realizado em junho de 1986, na sede da Organização Pan-Americana da Saúde (Opas), em Washington. Foi patrocinado pela Usaid em colaboração com Centers for Disease Control (CDC) e National Institute of Allergy and Infectious Diseases (National Institutes of Health)/Niaid (NIH), além do Fogarty International Center e da própria Opas (OMS). Seus resultados foram publicados em um suplemento de Reviews of Infectious Diseases, publicação oficial da Infectious Diseases Society of America (Bart et al., 1989). Esse volume especial, passados dez anos, é rico em pistas a serem seguidas quando nos debruçamos sobre um problema então apenas esboçado: o desenvolvimento de uma vacina para conter a epidemia de HIV/Aids.

Os temores do passado quanto aos riscos da vacinação estão ainda presentes. Porém, atenuados pelos flagrantes êxitos no controle de doenças pela vacinação em massa. O exemplo mais marcante é o da própria vacina antivariólica, emblemática desde sempre. A crise deflagrada no início deste século (1904), no Rio de Janeiro, contra o diretor-geral da Saúde Pública, Oswaldo Cruz, chegou a pôr em risco o governo do presidente Rodrigues Alves. Chamada Revolta da vacina, insurgiu-se contra a vacina antivariólica obrigatória, regulamentada por lei apelidada de "Código de Torturas" (ver a esse respeito Benchimol, 1990). Setenta anos após, a varíola estava erradicada do Brasil e do mundo, graças à vacinação em massa e à vigilância epidemiológica. O último caso selvagem, ou de transmissão natural (i.e., não laboratorial ou artificial) ocorreu na Somália, em 1977. O controle, embora não sendo erradicação, ou mesmo eliminação, de outras doenças transmissíveis provocadas por vírus (poliomelite, sarampo), bactérias (difteria, coqueluche) ou toxinas (tétano), criou uma nova imagem, tendente a atenuar os temores da vacina. Porém, não os erradicou. As representações sobre a vacina e o controle de doenças estão sendo, na atualidade, objeto de ativo processo de investigação, sobretudo por psicólogos sociais (ver Spink, 1994). Ousaria perpetrar metáfora que viria a calhar: o sucesso da utilização em massa de vacinas no controle de algumas doenças imunizou o senso comum contra a aversão às vacinas.

O que há de novo, especialmente condimentado pela agressiva presença de ONGs ligadas à epidemia HIV/Aids, é a emergência de controle social sobre os avanços da ciência, da tecnologia e da produção industrial de fármacos e vacinas. A globalização da economia e sua lógica de segmentação do mercado, dos monopólios, é contrabalançada, no pólo consumidor, pela vigilância ética da sociedade organizada. Transformar consumidores em cidadãos conduz, pelo menos na área dos fármacos, a uma concentração dos mecanismos decisórios de compra e distribuição. Conduz à compra exclusiva pelo Estado ou por comunidades de consumo: a monopsônio ou a oligopsônio. Especial atenção às drogas (e eventuais vacinas) órfãs, inventadas pelas grandes corporações farmacêuticas mas não industrializadas, nem muito menos comercializadas, por falta de mercado: só interessam aos mais pobres (pessoas e países). Cada vez mais se configura um quadro em que o desen- 
volvimento científico tem de devolver ao senso comum, à sociedade como um todo, seus avanços. A dupla ruptura epistemológica, ou como a define um autor (Santos, 1989) a "ruptura com a ruptura epistemológica", encontra aqui um terreno fértil a seu aprofundamento teórico.

\section{As iniciativas no campo da saúde}

Já comentamos o simpósio realizado na sede da Opas, em Washington, em 1986. Sua ênfase não é, obviamente, dirigida à epidemia HIV/Aids, que apenas é mencionada escassas três ou quatro vezes. Tentaremos extrair desse simpósio, realizado há mais de uma década, algumas linhas gerais do pensamento dos especialistas quanto ao ciclo completo do desenvolvimento de vacinas. Deixaremos para depois a incursão pelo terreno do objeto principal de nossas preocupações: a epidemia HIV/Aids. Deixaremos, ainda, de fora das considerações, as menções reiteradas ao Programa ampliado de imunizações, da OMS, amplamente esquadrinhado em todos os aspectos, especialmente na ainda hoje candente questão da distribuição e da cobertura ou, como se diz freqüentemente no jargão da área, na qualidade da $c a$ deia-de-frio e nas "oportunidades perdidas de imunização". Não nos deixemos, no entanto, enganar. As questões hoje colocadas quanto a uma vacina anti-HIV/Aids, uma vez equacionadas e, eventualmente, respondidas, não resolverão a maioria dos problemas com que se defronta a saúde pública, especialmente nos países subdesenvolvidos. A existência de uma vacina eficaz não conduz fatalmente à efetividade dos programas (ou campanhas) de vacinação. A crua realidade, em terrenos já bastante conhecidos da saúde pública mundial, não dá motivos para otimismo.

$\mathrm{Na}$ verdade, dez anos é muito tempo. Especialmente num terreno de tão grande dinamismo como o de desenvolvimento de vacinas. O simpósio é anterior à reunião da Cúpula da Criança, em Nova York, em 1990. Nesta, um grupo de cientistas entendeu que o mundo já possuía o desenvolvimento científico e tecnológico necessário para "aperfeiçoar vacinas existentes e desenvolver novas vacinas capazes de salvar as vidas de milhões de crianças (...) (e propuseram) um programa global que se chamou Children's Vaccine Iniciative (CVI)" (apud Homma, 1996). Estas idéias não conflitam com a necessária e indispensável movimentação quanto ao desenvolvimento de vacinas anti-HIV/Aids.

Em um contexto de estabelecimento de prioridades em saúde pública, no entanto, razões de custo $v s$. efetividade são geralmente aduzidas para justificar omissões. Brandir números competitivos não é monopólio dos advogados das crianças. O número de Lancet editado no sábado que antecedeu a abertura da XI Conferência Internacional de Aids, em Vancouver, Canadá, em julho de 1996, comete um editorial dedicado à "guerra ainda por vencer", contra o HIV (The Lancet, 1996). Considera egoístas os argumentos dos lobbies que exigem a redução do financiamento de pesquisas sobre doenças associadas ao HIV: os fundos destinados representam US\$ 110.00 por morte em Aids, contrastando com o dispêndio de apenas US\$ 1.85 por morte em acidentes vasculares cerebrais. De qualquer maneira, além dos riscos competitivos que fazem o prazer dos epidemiologistas modernos, há que 
levar em conta a competição de dentadas no orçamento global, desferidas por advogados de segmentos etários, étnicos, de portadores de doenças etc.

De todos os modos, a recentemente criada International Aids Vaccine Iniciative (Iavi) e a já referida CVI nos mostram uma linha de ação peculiar aos advogados de diversos matizes: criar estruturas chamadas iniciativas, geralmente internacionais e destinadas a sensibilizar quem tem dinheiro a empregá-lo em campo específico.

\section{As linhas mestras \\ de um simpósio digno de menção}

O Simpósio de Washington, realizado em 1986, utiliza uma abordagem formal do Institute of Medicine (IOM) para o estabelecimento de prioridades no desenvolvimento de vacinas (Hinman, 1989). Considera: carga total da doença, probabilidade de êxito no desenvolvimento da vacina, tempo previsto para registro (licensure), possível eficácia (e segurança) da vacina, exigências de distribuição e, finalmente, dificuldades técnicas de produção.

É evidente que esses critérios contextualizam a lista de prioridades. Não é por outra razão que o simpósio incorporou listas produzidas pelo IOM. Publicadas pela National Academy of Sciences, essas listas analisam separadamente as doenças de importância nos EUA e as doenças dos países subdesenvolvidos (developing). Ao comentar as listas, Jordan Jr. (1989) assinala o caráter falacioso, ou mesmo chauvinista, da divisão, e lembra que todas as doenças presentes nos países desenvolvidos também se encontram nos subdesenvolvidos. Aplicados os critérios, identificaram-se catorze doenças importantes para os EUA e 19 de importância internacional. Destas, seis já estavam na lista dos EUA, o que conduz à previsão de desenvolvimento de novas vacinas para 27 doenças na década seguinte (até 1996). Este é um dos poucos momentos em que se menciona o HIV, apenas para justificar que está excluído da análise e tem recebido atenção especial, inclusive predição, quanto à possibilidade de vacinas (em 1986, claro).

No terreno do conjunto de vacinas, identificaram-se dez necessidades prioritárias de pesquisa aplicada. Destas, três referem-se a questões de "engenharia", como cadeia-de-frio, injetores simplificados e baratos, em especial os operados a jato. Outras três são "bioquímicas", relacionadas com a potência, a estabilidade e os métodos diagnósticos simplificados. As quatro restantes são "pesquisas de campo" e referem-se a esquemas e calendários de vacinação, estratégias de erradicação (da poliomelite) e pesquisa operacional (gerência, vigilância, avaliação). Ver Hinman (1989), especialmente no comentário a respeito da "ciência e tecnologia (estarem) muito à frente da utilização". A pesquisa de campo fica, assim, excluída do desenvolvimento em ciência e tecnologia!

Outra apresentação importante no simpósio é o texto de Petricciani et al. (1989) sobre "obstáculos e oportunidades, da descoberta ao uso". Veja-se o excerto: "A produção de uma vacina efetiva depende da habilidade de manufaturar grandes 
quantidades de antígeno seguro, capaz de estimular imunidade protetora quando aplicado em seres humanos. Existem diversos aspectos não-científicos (grifo nosso) que podem inibir o desenvolvimento de uma vacina. $\mathrm{O}$ mais importante de todos - em países onde a indústria de biológicos visa o lucro - relaciona-se ao interesse do setor privado em investir num projeto de vacina. Custa muito dinheiro inventar novas vacinas e oferecê-las ao público: as companhias capazes de investimentos deste porte relutam em aplicar grandes somas sem terem certeza de um retorno financeiro. As incertezas do mercado de vacinas estão baseadas: 1) no tamanho do mercado (i.e., qual o tamanho da população para a qual se recomenda a vacina-nacional e internacionalmente); 2) quem pagará pela vacina (indivíduo, governo, agências internacionais); 3 ) riscos de prejuízo".

Esta extensa citação visa fundamentalmente à ampliação do âmbito do debate. Não se refere ao HIV/Aids, mas sim ao conjunto dos interesses das indústrias produtoras de vacinas. Os autores (Petricciani et al., 1989) pertenciam na época aos quadros da OMS, em Genebra. Embora mencionem que o afirmado para empresas com fins lucrativos vale, em certa medida, também para empresas de países onde a indústria é estatizada, passam a considerar o prejuizo potencial como problema magno. A lógica de um mercado globalizado coloca em risco a saúde de milhões de pessoas, em todo o mundo. Em particular na área das doenças preveníveis por vacinas, o que a Aids ainda não é. Quando, e se, vier a sê-lo, ocorrerão os mesmos constrangimentos extensamente descritos em outras áreas da saúde pública.

Um último comentário, ainda baseado nas apresentações do simpósio. Refiro-me ao texto, sintético e incisivo, de Osborn (1989) na introdução ao capítulo sobre "desenvolvimento de vacinas". Chama a atenção para a capacidade que a humanidade tem em banalizar os eventos mais surpreendentes, até "desastres e horrores". Refere-se ao esquecimento dos grandes fantasmas do passado (epidemias, entre outros). No terreno da prevenção, isto é catastrófico e culmina, o que é pior, pela "rapidez com que as maravilhas da criatividade humana, no caso as inovações em vacinas, são rapidamente subsumidas pelos tediosos problemas envolvidos nos esforços de distribuição". Justifica sua apreensão com uma das poucas menções à Aids em todo o volume dedicado ao seminário. Esquecida do terror ancestral das doenças infecciosas, a sociedade norte-americana foi rudemente atingida pela epidemia de Aids. Sua maior esperança estava precisamente na possível criação de uma vacina capaz de contê-la. Ao mesmo tempo, no entanto, a "disponibilidade de vacinas para doenças familiares estava ameaçada por razões relacionadas com possível prejuízo financeiro (dos produtores), má interpretação das análises custo vs benefício vs risco, além dos equívocos a respeito de riscos potenciais associados à vacinação".

Mais uma vez, o conhecimento gerado pelo "trabalho de campo" é considerado injustamente como capaz apenas de eliminar o tédio da distribuição, que "subsumiu" o verdadeiro conhecimento científico, maravilha da criatividade humana. 


\section{A controversa}

\section{vacina anti-HIV/Aids}

Com a descoberta do vírus HIV, inúmeras mudanças ocorreram no sistema científico-tecnológico-industrial da área da saúde. O paradigma pasteuriano encontrava um terreno mais seguro, conhecido há décadas e por onde transita com desenvoltura. A pendência sobre a autoria da descoberta do vírus não significa apenas um necessário reconhecimento do mérito científico. Está em causa a questão da propriedade intelectual e, por decorrência, do direito de patente. Não é dizer pouco: a isto associa-se a patenteação dos testes de laboratório para detecção da infecção por HIV e seu formidável potencial de lucro. Descoberta a maneira de diagnosticar a infecção (HIV), antes que a doença (Aids) se manifeste, produziu-se uma imensa transformação dos procedimentos preventivos convencionais e uma avalanche de medidas antiéticas e discriminatórias em relação aos portadores do HIV.

O corolário da teoria do germe apontava, obviamente, para a possibilidade de invenção de uma vacina anti-HIV. Esta, foi controversa desde o início. Do ponto de vista das disciplinas biomédicas, as principais dúvidas ainda persistem e os esforços para avançar esbarram em obstáculos de tríplice natureza: a) extraordinária habilidade de mutações do HIV; b) incapacidade dos anticorpos anti-HIV em neutralizar consistentemente os isolados primários (selvagens) do vírus; e c) desconhecimento a respeito dos correlatos de imunidade protetora nas infecções por HIV (ver a propósito Haynes, 1996).

Outros argumentos têm sido levantados, até a possibilidade da produção de anticorpos facilitadores, induzidos pela vacina anti-HIV. Os indivíduos inoculados não apenas não estariam protegidos: os anticorpos produzidos facilitariam uma (posterior e eventual) infecção natural pelo HIV (selvagem). Não é este o melhor local para aprofundar a discussão a respeito da discórdia no ambiente da pesquisa biomédica. É necessário, porém, ter em mente que ela existe: não há consenso entre cientistas básicos quanto à viabilidade de inventar uma vacina anti-HIV capaz de contornar os obstáculos impostos. Pelo menos, atualmente. Nem nos próximos anos, para desgosto da comunidade científica e da humanidade. Sem mencionar a maneira persistente com que um cientista norte-americano, Duesberg, nega a natureza causal da associação entre HIV e Aids. Essas objeções, não aceitas pela comunidade científica, foram esquadrinhadas por Grmek (1994) que, embora assinale que "não se possa aceitar uma negação radical da teoria viral da Aids", os argumentos de Duesberg nem sempre são equivocados e fáceis de contestar.

Apesar das controvérsias, a biotecnologia moderna produziu protótipos de vacinas anti-HIV/Aids, ou candidatos a vacina, empregando diversos modelos, ou conceitos. Propuseram-se: proteínas do envelope do vírus, peptídios sintéticos, vetores (vírus geneticamente manipulados também chamados quimeras, exemplos: vaccinia e canarypox), partículas com algumas proteínas do HIV. Chega-se ao extremo de propor, à semelhança de vacinas virais largamente empregadas, vírus mortos (raiva) ou mesmo atenuados (poliomelite, tipo Sabin). Existe uma vasta biblio- 
grafia a respeito. Vejam-se, a propósito, as publicações recentes do Iavi Report, editado pela International Aids Vaccine Iniciative, ou, no Brasil, um Caderno técnico editado pelo Ministério da Saúde (Brasil, 1994).

\section{A controvérsia}

\section{da vacina no mundo}

Passar da invenção de uma vacina no laboratório para a aplicação no mundo real, em larga escala, é um longo caminho. A grande controvérsia atual nos remete aos tempos heróicos do próprio Pasteur. Para usar a metáfora de Lambrichs (1993): será que já "sabemos nadar"?

Não apenas a ciência se transformou. Após a Segunda Guerra Mundial, rigorosos códigos de ética controlam a realização de experimentos científicos no homem. Nem sempre conseguimos exercer uma vigilância ética sobre os ensaios clínicos, realizados geralmente com número reduzido de voluntários. O consentimento informado assinado pelos participantes (sujeitos do ensaio e pesquisadores), nem sempre é perfeitamente compreendido. Porém, um ensaio epidemiológico de campo para cálculo da eficácia do produto (vacina) dificilmente passa despercebido da imprensa, do público em geral e, especialmente, dos ativistas das ONGs. A controvérsia assume sua dimensão de questionamento ético.

Mas não é só. Um ensaio de campo, feito com rigor para medir com alguma precisão numérica o resultado alcançado, deve obedecer preceitos epidemiológicos e estatísticos. Violar estes preceitos pode ser tão grave quanto violar as boas práticas de laboratório (GLP), na pesquisa e desenvolvimento, ou as boas práticas de produção (GMP), na indústria. Dizem respeito, fundamentalmente, ao ensaio de eficácia, ou fase III do desenvolvimento de uma vacina.

Inventado o princípio ativo, no laboratório de pesquisa básica, ele passa por uma fase chamada pré-clínica. Esta realiza-se inicialmente em modelos estritamente laboratoriais (axênicos) e passa, quando possível, a modelos animais. O modelo animal, nos estudos de HIV, emprega macacos: usa o próprio vírus humano ou seu equivalente simiano, o SIV. São modelos dispendiosos e complexos, somente possíveis em um número limitado de instituições. Seus resultados, embora controversos, são considerados promissores (Johnston, 1996).

Nos países em que o controle é rigoroso, os protocolos sobre o novo produto e os resultados dos ensaios pré-clínicos são encaminhados ao organismo regulamentador (FDA, nos EUA). Uma vez aprovados, o produtor é autorizado a realizar ensaios clínicos. Na fase I testa-se apenas a segurança do produto. É inoculado em poucos (dezenas) indivíduos, geralmente distanciados da possibilidade de adquirir infecção natural. Nas vacinas para aplicar em crianças é comum realizar esta fase I em adultos jovens (recrutas do exército, por exemplo). Acompanhada rigorosamente, laboratorial e clinicamente, a fase I termina por demonstrar se a nova vacina é (ou não) segura: sem efeitos adversos graves. Um grupo de controle recebe um placebo, para comparar os resultados. 
Novamente submetidos ao órgão regulamentador, os resultados conduzem, quando favoráveis, a uma autorização de passar à fase II. Nesta, avalia-se a imunogenicidade, ou poder de produzir imunidade do novo produto. Depende, obviamente, da existência de modelos químicos ou biológicos (às vezes, animais) de medir a imunidade. Não passa pela cabeça do meio científico ético realizar testes de desafio: inocular o agente patogênico nos voluntários vacinados. No passado, a ciência fez muitos mártires: cientistas usaram a si próprios como animais de teste para estes desafios e, lamentavelmente, ainda não tinham "aprendido a nadar". A fase II é realizada em um número maior (centenas) de voluntários e controles, também submetidos a um rigoroso acompanhamento clínico e laboratorial. No caso das vacinas da infância, estudantes de segundo grau têm sido o alvo preferencial. Aproveita-se, na fase II, para iniciar os estudos da melhor estratégia para uso do novo produto: via de aplicação (injeção muscular ou subcutânea, via oral etc.); doses; número de aplicações e intervalo entre elas etc.

Nas duas primeiras fases, o controle rigoroso dos voluntários torna o processo um verdadeiro ensaio clínico. Na fase III testa-se a eficácia do produto. O número de voluntários é bem maior (milhares) e o controle individual menos rigoroso: é um estudo epidemiológico, de campo ou de mundo real. O alvo são os mais vulneráveis: as próprias crianças pequenas nas vacinas próprias para a idade. Calcula-se a incidência da doença para a qual a vacina é proposta em dois grupos: vacinados e não-vacinados. O ensaio é um duplo-cego: nem os voluntários nem os trabalhadores de campo sabem a que grupo pertence cada um deles. Espera-se que o grupo vacinado tenha incidência menor da doença. Uma equação simples transforma as incidências calculadas em cada grupo na medida da eficácia, obviamente positiva: os vacinados devem ter incidência menor. Aqui existem vários problemas operacionais, inerentes ao trabalho de campo com grandes grupos de voluntários. Não são desprezíveis: existe uma competência científica própria, associada ao trabalho epidemiológico, tão importante quanto as "boas práticas de laboratório" e "boas práticas de produção" das fases pré-clínicas, e o rigor clínico e novas "boas práticas de laboratório" nas fases clínicas anteriores (I e II).

No desenvolvimento das vacinas anti-HIV/Aids já foram propostos cerca de trinta novos produtos. Dada a complexidade do campo específico, juntaram-se as fases clínicas I e II em ensaios conjuntos, geralmente realizados em grupos de vinte a cinqüenta voluntários. Nos diversos ensaios, produtos candidatos a vacina foram aplicados até o início de $1997 \mathrm{em}$ mais de dois mil pessoas. Alguns problemas são relatados. Desconhecendo-se rigorosamente os correlatos da imunidade protetora, os anticorpos medidos apenas indicam que o organismo reagiu à inoculação do produto. Espera-se, sem ter certeza, que isso indique proteção. As reações adversas graves praticamente não ocorreram, o que é um bom sinal. Porém, alguns voluntários, inoculados com produtos que não poderiam ocasionar a infecção (peptídios, proteínas etc.), adquiriram-na naturalmente (pelas vias usuais: contato com sangue, transmissão sexual etc.). A maioria pertencia ao grupo de controle, isto é, voluntários inoculados com um placebo e não com a vacina. Este fato, por si só, denuncia uma 
violação dos princípios seguidos no processo normal de desenvolvimento de vacinas: nas fases I e II usam-se voluntários de pequena vulnerabilidade. O mais surpreendente é que, em alguns casos, apresenta-se a inexistência de casos de infecção natural entre os vacinados como argumento favorável. Aos ensaios não formulados para avaliar incidência não é lícito aduzir este tipo de argumento.

Na passagem para a fase III nos ensaios de vacina HIV/Aids alguns problemas adicionais são lembrados. Um dos mais candentes prende-se ao estigma que ainda acompanha as pessoas soropositivas (HIV positivas). Ao produzirem anticorpos, que não se tem a certeza de serem necessariamente protetores, os voluntários vacinados tornam-se HIV positivos, o que pode vir a lhes causar transtornos pessoais em um mundo ainda dominado por preconceitos contra grupos de risco. Outro diz respeito à possível violação do sigilo do ensaio duplo-cego. Os voluntários podem desvendar o mistério que cerca a injeção que receberam, submetendo-se a um teste sorológico em um centro de testagem anônima. Sendo HIV positivos saberão que receberam a vacina. Podem descuidar das práticas de prevenção (sexo seguro, por exemplo) aconselhadas, por razões éticas, pelo pesquisador que conduz o ensaio. Se isto ocorrer em grande escala o resultado final pode vir a ser o inverso do esperado: tratando-se, na fase III, de um grupo de alta vulnerabilidade e, se a eficácia provável da vacina não for elevada, o grupo vacinado pode chegar a ter incidência maior, $o$ que conduz ao absurdo de uma eficácia negativa!

Estes argumentos fizeram com que alguns estatísticos chegassem a propor testes bicaudais para comparar as incidências entre os dois grupos em estudo. Estes dois incovenientes têm sido questionados: os produtos até agora testados em fases I e II não se mostram capazes de produzir conversão detectável pelos exames sorológicos convencionais. Outro problema diz respeito ao tamanho dos grupos, ao tempo de acompanhamento e, por decorrência, aos custos dos ensaios de campo. Os grupos de elevada vulnerabilidade com adesão elevada aos estudos e, portanto, com pequena proporção de abandono, geralmente estão sujeitos a incidências modestas da infecção pelo HIV, raramente superiores a duas em cada cem pessoas por ano. Para conseguir boa precisão na medida de eficácia (provavelmente baixa) nestas circunstâncias são necessários muitos milhares de voluntários, acompanhados por períodos longos (ao menos dois ou três anos), ao custo de muitos milhões de dólares. Todas essas razões, epidemiológicas e financeiras, fizeram com que os EUA, país onde se realizou a maioria dos testes em fases I e II, ainda não tivessem aprovado, no início de 1997, ensaios em fase III. Com o recente anúncio presidencial, esperam-se novidades.

Antes do anúncio do presidente dos EUA, em maio de 1997, assumindo como missão nacional histórica a produção de vacina eficaz contra HIV/Aids, vários acontecimentos tornaram inviável a realização de testes de eficácia no país. Para citar apenas o episódio mais marcante, recordemos os acontecimentos de junho de 1994, numa reunião do Niaid/NIH, realizada em Bethesda, que ganharam a imprensa não especializada. Dois meses antes, em abril, um comitê assessor havia recomendado seguir adiante com a proposta de ensaios de fase III, apesar da imper- 
feita compreensão do significado dos anticorpos produzidos pelos voluntários inoculados em termos de proteção. Argumentava que de pouco ou nada adiantaria prosseguir em estudos de laboratório, ou mesmo com modelos animais, para ganhar no conhecimento do papel protetor das vacinas experimentais. Na reunião de junho, mais ampla, estiveram presentes membros do Subcomitê de Aids (do Conselho Assessor do Niaid) e membros do Aids Research Advisory Committee (Arac, dependente do Congresso dos EUA). A reunião foi aberta ao público, a quem se deu oportunidade para expor suas inquietudes. Contrariamente ao que havia sido aconselhado em abril, a nova reunião desaconselhou avançar para estudos de eficácia (fase III) em virtude das incertezas e dos custos previstos para tais ensaios. Pesou, entre outros argumentos, a ameaça de boicote dos ensaios tanto nos EUA, quanto no exterior, por parte dos grupos de ativistas presentes, notadamente do Act Up (Nova York). Ver, a respeito, as referências: Altman (1994), Niaid (1994), Act Up (1994).

Os acontecimentos motivaram o prognóstico de um diretor do NIH quanto ao "arrefecimento" da indústria em seu esforço para produzir novas vacinas antiHIV/Aids.

\section{O Brasil "aprende a nadar"}

Os acontecimentos de junho de 1994, nos EUA, causaram estardalhaço entre cientistas e sanitaristas em todo o mundo. No Brasil, há pelo menos dois anos já se havia formulado um Plano Nacional de Vacinas HIV/Aids e criado um comitê para conduzi-lo. Na OMS, em Genebra, havia, então, um Global Programme on Aids (GPA), que incluía um departamento dedicado ao tema: Vaccine Development. Os mal-entendidos iniciais já haviam sido superados: na primeira tentativa de aproximação o Ministro de Saúde do Brasil repudiara a iniciativa, afirmando que o país não se prestaria ao papel de cobaia.

O Brasil está engajado no esforço global do GPA para testar vacinas antiHIV/Aids. O programa contempla quatro tipos de atividades: 1) rastreamento dos subtipos (clades) de HIV-1 em circulação no mundo, pelo isolamento e caracterização de fenótipo e genótipo de amostras do HIV de indivíduos recém-infectados (soroconvertores); 2) estudos clínicos sobre a história natural da infecção e ensaios de fases I e II de vacinas candidatas; 3 ) estudos epidemiológicos em segmentos da população, compondo coortes (grupos) de pessoas HIV negativas para cálculo de incidência, visando estabelecer a factibilidade de futuros ensaios de fase III; e 4) estudos sociocomportamentais, especialmente entre os voluntários participantes das coortes de estudos de incidência, visando não só elucidar as práticas prevalescentes na coorte que aumentam sua vulnerabilidade, como também avaliar a disposição de voluntários em participar de ensaios de eficácia e a aceitação social quanto a sua realização.

Escolheram-se, por razões epidemiológicas e de viabilidade, quatro países subdesenvolvidos: Brasil, Ruanda, Uganda e Tailândia. Definiram-se vinte coortes, 
sendo três no Brasil - Belo Horizonte, Rio de Janeiro e São Paulo. Posteriormente, uma quarta coorte foi criada, também no Rio de Janeiro, vinculada à rede do NIH (Hivnet). No Brasil, o trabalho de acompanhamento das coortes, iniciado em 1994, segue em circunstâncias que sugerem terem sido satisfeitos os requisitos prévios a estudos de factibilidade: todas as coortes conseguiram recrutar acima do número exigido de voluntários (quinhentos) e mantê-los em seguimento por períodos longos (até três anos). Não é este o momento de discutir os resultados desses estudos. Interessa-nos, antes, examinar as perspectivas do seu prosseguimento em vista dos desdobramentos do tema no cenário mundial.

Considerando os números previstos nas 20 coortes dos quatro países chegamos a 15.980 voluntários, o que representa um esforço admirável. Os recentes acontecimentos políticos em Ruanda tornaram inviável a continuidade dos trabalhos. Perderam-se, assim, dez coortes com 2.900 voluntários previstos. Ainda assim, permaneceram outras dez coortes, com 13.080 voluntários. As três coortes brasileiras, todas recrutando homens homo ou bissexuais (homens que fazem sexo com homens - HSH) conseguiram superar o número previsto de 500 voluntários. A quarta coorte, ligada à Hivnet, também demonstra vitalidade. Nos demais países, Uganda e Tailândia, pelas notícias freqüentes em publicações especializadas e até pelos contatos pessoais entre os investigadores principais dos projetos, os trabalhos também prosseguem de maneira promissora [ver a propósito Iavi Report $(1996,1997)$ e Uganda (1996)].

No Brasil, além da formação e acompanhamento das coortes, foram realizados ensaios de fase I e II, com produto fornecido por laboratório norte-americano. Inocularam-se, em Belo Horizonte e no Rio de Janeiro, trinta voluntários. Os resultados foram favoráveis, pelo menos quanto à segurança do produto.

Quando tudo parece caminhar num mar de rosas ocorrem transformações sérias que causam apreensão. Quando "aprendemos a nadar”, aparece uma proposta de mudança da competição: automobilismo, não mais natação!

\section{A vaca gorda, ou greed $=$ death}

O prognóstico do diretor do NIH, ao término da reunião de junho de 1994, não estava longe da verdade. Para conter o prenunciado arrefecimento da indústria, tomaram-se algumas iniciativas imediatas. Já em outubro do mesmo ano, o GPA/ OMS convocou a Genebra os principais interessados para um Meeting on scientific and public health rationale for HIV vaccine efficacy trials. Estiveram presentes a comunidade científica, sanitaristas, representantes de ONGs e da indústria farmacêutica, além do pessoal da OMS. As conclusões e recomendações do encontro, após transitar pelo estado da arte do conhecimento na área, propõem que se prossiga nos esforços para a realização de ensaios de eficácia (fase III) dos produtos existentes. Fala em testes de conceito e conclui com a obviedade: a decisão tomada pelos EUA só vale para ensaios no território norte-americano, o que não impede que se realizem testes em outros países, até mesmo por laboratórios e pesquisadores 
estadunidenses, desde que seja respeitada a soberania dos países onde os ensaios forem realizados. Até então, ninguém suspeitava que as soberanias nacionais estavam sujeitas a esse risco! (ver a respeito GPA/WHO, 1994).

Três outros acontecimentos têm relevância no contexto. Já em março de 1994, a Rockefeller Foundation havia propiciado uma reunião internacional, em Bellagio, Itália, com a finalidade de discutir as possibilidades de "acelerar o desenvolvimento de vacinas preventivas anti-HIV para o mundo". Partia das preocupações com o andamento da epidemia, cada vez mais concentrada nos países subdesenvolvidos, notadamente da África, e suas perspectivas de explosão na Ásia. As agências financiadoras dos países desenvolvidos e as poderosas indústrias farmacêuticas e de biotecnologia deveriam ser incentivadas a entrar em cooperação com os países subdesenvolvidos para acelerar os estudos sobre o tema. O discurso do relatório final é uma reativação da polêmica que invadiu o campo das vacinas desde os tempos de Pasteur: qual é o momento mais propício para nos atirarmos à água? $\mathrm{Ou}$, se quisermos mudar a metáfora, as competições automobilísticas da atualidade são repletas de risco para os pilotos, mas permitem o aperfeiçoamento das máquinas e, por isso, são financiadas pela indústria (de automóveis, pneus, combustível etc.). Duas conclusões dominam o Sumário Executivo da reunião: 1) o desenvolvimento e os testes das múltiplas abordagens empíricas, conduzidos em paralelo e não de maneira seqüencial, configuram a maneira mais rápida para desenvolver vacinas seguras, eficazes e baratas; 2 ) para concretizar esse desígnio deve ser estabelecida uma nova iniciativa, que advogue os princípios expressos na reunião [ver a respeito Rockefeller Foundation (1994)].

Estava proposta a criação da International Aids Vaccine Initiative (Iavi), que passou a movimentar-se com desenvoltura, realizando sucessivas reuniões, estabelecendo prioridades e buscando parcerias para tornar exeqüível financeira, científica e eticamente seus propósitos. Longe de nós a paranóia de ver em tudo o que se propõe nos países centrais sempre uma maquiavélica má intenção. Porém, é indiscutível a tendência da nova proposta: atirar-se à água antes de saber nadar direito, reciclada para a metáfora do aprimoramento da indústria automobilística.

Os outros dois acontecimentos ocorreram, ambos, em 1995. Em primeiro lugar, o NIH dos EUA reviu suas propostas de desenvolvimento de pesquisas em Aids (ver Niaid/NIH, 1995 e 1995a). No caso específico dos ensaios de eficácia (fase III), assume a dificuldade de prosseguir com sua proposta original. Considerando as baixas incidências nos grupos de voluntários capazes de ser seguidos por longos períodos, sugere ensaios intermediários ou testes de conceito. Fiel à tradição inaugurada por Jenner dois séculos antes, "obviando a aleatoridade" com ensaio num único voluntário, o NIH propõe violar as exigências estatísticas de precisão das medidas de incidência, estimando a eficácia com intervalos de confiança maiores do que os usuais, por exemplo, mais ou menos 30\%. Imagina que os ensaios se multiplicarão em dezenas, ou mesmo centenas, de lugares em todo o mundo. Desta forma, irão sendo aprimorados os conceitos propostos para a criação de vacinas, sejam eles proteínas da cápsula do HIV, peptídios ou quimeras (vetores genetica- 
mente manipulados), propiciando redirecionamentos necessários no caso de não se conseguirem evidências suficientes para o acerto das iniciativas.

Em outra mudança, ainda no mesmo ano, a OMS decidiu que o GPA deixaria de existir a partir de janeiro de 1996. Foi substituído por uma nova agência das Nações Unidas: Joint United Nations Programme on HIV/Aids, ou Unaids. Agrupa seis agências da ONU, todas elas com presença ativa na resposta à epidemia: Unicef, Undp, Unfpa, Unesco, WHO e World Bank. Com orçamento modesto e corpo de técnicos pequeno, não é declaradamente uma agência de financiamento. Segue considerando o desenvolvimento de vacinas HIV/Aids como prioridade, porém não mais com garantia de suporte às coortes compostas por iniciativa do GPA/WHO em países subdesenvolvidos. A Unaids assumirá mais propriamente um papel de advocacia: lutará por sensibilizar governos de países ricos e pobres, fundações internacionais e, especialmente, a indústria farmacêutica para dar prosseguimento aos estudos de desenvolvimento de vacinas HIV/Aids. Aparentemente, no terreno específico das vacinas, um papel coincidente com as propostas da recémcriada Iavi. Estamos bem servidos de iniciativas [ver a propósito Onusida (1995) e Unaids (1996)].

O mundo vive um clima curioso, e o Brasil o acompanha com perplexidade. A globalização da economia coloca um desafio inesperado para a humanidade. Mecanismos globais de controle começam a ser propostos: a transformação das agências das Nações Unidas em verdadeiros instrumentos de ação de importância renovada com a previsível extinção dos estados-nação no século XXI. O Banco Mundial e o FMI exerceriam, efetivamente, os papéis reservados, na atualidade em nosso país, ao Banco do Brasil e ao Banco Central, respectivamente. A FAO seria um Ministério da Agricultura do Mundo e a OMS seu Ministério da Saúde (Tinbergen, 1994). Nesta perspectiva, os poderosos seguirão como tal. Que será dos humildes?

O XI Congresso Internacional de Aids, em Vancouver, em julho de 1996, foi marcado, desde a sessão de abertura até a de encerramento, pelo protesto dos ativistas das ONGs, notadamente os diversos Act Up de Nova York, Golden Gate e Philadelphia. O principal alvo foi a ganância (greed) dos laboratórios farmacêuticos e os preços exorbitantes dos medicamentos reunidos em esquema (coquetel), no qual se depositam as esperanças de maior sobrevida para as pessoas vivendo com HIV. Associavam com ênfase a ganância à morte, gritando palavras de ordem e distribuindo panfletos com a mensagem incisiva: greed $=$ death. Os ativistas literalmente destruíram os quiosques de propaganda dos laboratórios farmacêuticos, instalados no recinto do congresso. Era motivo de expectativa de todos saber qual seria o alvo de cada dia: ao iniciar-se a movimentação, com apitaço, todos se deslocavam atrás dos ativistas até que se chegava ao laboratório escolhido. Já escrevi sobre o episódio, comparando-o ao que se poderia esperar de luditas pós-modernos (Carvalheiro, 1997). O congresso culminou, na sessão de encerramento, com sonora vaia, não apenas dos ativistas mas da quase totalidade do plenário, ao representante da instituição promotora, a International Aids Society. Este anunciou, como 
grande conquista, ter conseguido dos laboratórios farmacêuticos a garantia de que tratariam todos os participantes de ensaios clínicos de drogas cuja eficácia se conseguisse comprovar. Mesmo os participantes dos grupos-controle receberiam a nova droga, após a conclusão do estudo.

Neste clima, a perspectiva dos países subdesenvolvidos será a de seguirem sendo local de realização de ensaios arriscados? É difícil afirmar. Porém, a idéia de testar conceitos, a proposta de realizar de maneira concomitante o desenvolvimento dos novos produtos (= conceitos) e seus testes de campo (natação ou automobilismo?) nos causam preocupação, para dizer o menos. Se quisermos dizer mais, é mister assegurar a manutenção das pontes que ligam as ONGs e seus ativistas aos cientistas e aos sanitaristas, especialmente, mas não apenas, dos países subdesenvolvidos. Recuperar o prestígio das pesquisas no âmbito das ciências humanas, realçando a epidemiologia como disciplina instrumental dos testes de eficácia. Em um mundo científico que compreenda que o esforço multidisciplinar é essencial para o desenvolvimento da ciência, o trabalho de campo tem a mesma importância do realizado no laboratório, por mais requintada que seja a parafernália tecnológica a este associada. Um não se realiza sem o outro. No sentido mais profundo do que significa realizar-se.

Um comentário derradeiro. As vacinas viveram, desde sempre, sob a influência das vacas. Sua própria designação tem essa origem, por mais complexos que sejam os atuais procedimentos de desenvolvimento e produção. Na medida exata em que uma epidemia se pauperiza, tornando-se, à semelhança da hanseníase, uma endemia quase exclusiva do mundo subdesenvolvido, arrefecem os estímulos para a indústria farmacêutica continuar com seus esforços de pesquisa, desenvolvimento e produção de fármacos e vacinas. Tornam-se vacas magras. A complexa dinâmica da epidemia de Aids no mundo, no século XXI, das forças sociais e econômicas, do processo de globalização (econômica e da informação) ditará os rumos da cobiça: a vacina anti-HIV/Aids poderá ou não ser uma vaca gorda para a indústria. E o presidente dos EUA poderá cumprir com sua promessa enfática apenas parcialmente. A ciência e a tecnologia poderão criar uma vacina de grande eficácia, porém razões de natureza econômico-financeira reduzirão sua efetividade no controle da epidemia. Não é improvável que a vacina seja um organismo geneticamente alterado, uma quimera biológica real. Também é possível que venha a ser uma quimera no sentido figurado (Carvalheiro, 1995, citando Grmek, 1995).

Referências bibliográficas

ACT UP/NEW YORK. Large scale vaccine trials. Letter to the members of the Aids Research Advisory Committee. Treatment and Data Committee, jun. 1994.

ALTMAN, L. K. Panel rejects wider testing to develop Aids vaccine. New York Times, jun. 1994. 
BART, K. J.; HINMAN, A. R. \& JORDAN Jr., W. S. (eds.). International Symposium on Vaccine Development and Utilization. Reviews of Infectuous Diseases, vol. II, suppl. 3, p. S491-S667, 1989.

BENCHIMOL, J. L. (coord.). Manguinhos do sonho à vida - a ciência na Belle Époque. Rio de Janeiro, Fundação Oswaldo Cruz, 1990.

BRASIL. Ministério da Saúde. Vacinas contra HIV/Aids. Série Cadernos técnicos n ${ }^{0} 1$. Brasília, PN-DST/Aids, 1994.

BUCK, C.; LLOPIS, A.; NÁJERA, E. \& TERRIS, M. The challenge of epidemiology, issues and selected readings. Washington, DC, Pan American Health Organization, Scient Public, $\mathrm{n}^{\circ} 505,1988$.

CARVALHEIRO, J. R. Quimera pode ser a solução para a Aids. O Estado de S. Panlo, Caderno 2, Especial-Domingo, p. D-3, 02/07/95.

Epidemia de Aids. In: TRENCH, B. (org.). Almanque Zero. São Paulo, Nepaids, 1997, p. 18-19.

GADELHA, C. A. G. Apresentação do debate: a produção e o desenvolvimento de vacinas no Brasil. História, ciências, saúde - Manguinhos 3(1): 111-113, 1996.

GPA/WHO. Scientific and public health rationale for HIV vaccine efficacy Trials. Meeting on Geneva, out. 1994. Final conclusions and recommendations, list of participants and a note to correspondents. Geneva, WHO/GPA, 1994.

GRMEK, M. Dark sides of the virological causal explanation of Aids. Croatian Med. J. 35(1): 12-18, 1994.

Histoire du sida. Début et origine d'une pandémie actuelle. Paris, Payot, 1995 (Petite Bibliothéque).

O enigma do aparecimento da Aids. Estudos Avançados 9(24): 229-239, 1995.

HAYNES, B. F. HIV vaccines: where we are and where we are going. Lancet 348: 933$937,1996$.

HINMAN, A. R. Vaccine development and utilization: summary of the symposium. In: BART, K. J. et al. (eds.). Op. cit., Rev. Infec. Dis., vol II, suppl. 3, p. S663-S666, 1989.

HOMMA, A. Intervenção no debate: a produção e o desenvolvimento de vacinas no Brasil. História, ciências, saúde-Manguinhos 3 (1): 111-132, 1996.

IAVI Report. A newsletter on international Aids vaccine research. Vol. $1, \mathrm{n}^{\circ} \mathrm{l}$, summer 1996. New York, Iavi, 1996.

IAVI Report. A newsletter on international Aids vaccine research. Vol. $2, \mathrm{n}^{\circ} \mathrm{l}$, winter 1997. New York, Iavi, 1997.

IAVI Report A newsletter on international Aids vaccine research. Vol. $2, \mathrm{n}^{\circ}$ 2, summer 1997. New York, Iavi, 1997a.

JOHNSTON, M. Why an HIV vaccine is scientifically possible? Iavi Report l(1): 1-11, 1996. 
JORDAN Jr., W. S. Impediments to the development of additional vaccines: vaccines against important diseases that will not be available in the next decade. In: BART, K. J. et al. (eds.). Op. cit., Rev. Infec. Dis., vol. II, suppl. 3, p. S603-S612, 1989.

LAMBRICHS, L. L. La vérité médicale: Claude Bernard, Louis Pasteur, Sigmund Freud: légendes et réalités de notre médecine. Paris, Robert Laffont, 1993 (Colecction Pluriel).

NIAID. Joint meeting of the Aids Subcommittee of the National Advisory Allergy and Infectious Diseases Council and the Aids Research Advisory Committee. Bethesda, Maryland, jun. 1994.

NIAID/NIH. HIV/Aids vaccine research and development - strategy and opportunity. Bethesda, NIH, 1995.

NIAID/NIH. HIV/Aids, research agenda. Bethesda, NIH, 1995a.

ONUSIDA. Hoja de información sobre Onusida. Genebra, Onusida, XI Reunión del Comité de Administración del Programa Mundial del Sida (PMS), abr. 1995.

OSBORN, J. E. Vaccine development: introduction. In: BART, K. J. et al. (eds.). Op. cit., Rev. Infec. Dis., vol II, suppl. 3, p. S518, 1989.

PETRICCIANI, J. C.; GRACHEV, V. P.; SIZARET, P. P. \& REGAN, P. J. Vaccines: obstacles and opportunities from discovery to use. In: BART, K. J. et al. (eds.). Op. cit., Rev. Infec. Dis., vol II, suppl. 3, 1989.

ROCKEFFELER FOUNDATION. HIV vaccines: accelerating the development of preventive HIV vaccines for the world. Summary Report and Recommendations of an International Meeting. Bellagio, Italy/New York, Rockeffeler Foundation, mar. 1994.

SANTOS, B. S. Introdução a uma ciência pós-moderna. Rio de Janeiro, Graal, 1989.

SPINK, M. J. P. Preparação para o desenvolvimento de vacinas anti-HIV/Aids: aspectos relacionados ao recrutamento e manutenção de voluntários. Apresentação no Seminário sobre Vacinas anti HIV/Aids: problemas e benefícios. Cooperação Brasil/ França, Rio de Janeiro, jul. 1994.

The Lancet. Editorial. HIV: a war still to be won. Lancet 348:1, 1996.

TINBERGEN, J. Global governance for the $21^{\text {st }}$ century. Human Development Report. New York, Undp/Oxford University Press, 1994.

UGANDA, MINISTRY OF HEALTH. HIV candidate vaccine trial workshop. Kampala, Ministry of Health, set. 1996.

UNAIDS. Fact sheet. Geneva, Unaids, jul. 1996.

Resumo - A história do controle de doenças pela vacinação é relativamente recente, remonta a pouco mais de duzentos anos. Propostas no início empíricas ganharam força no século XIX com a emergência da Teoria do Germe, paradigma ainda vigente nas ciências da saúde. O desenvolvimento atual da biotecnologia, ao mesmo tempo supera as dificuldades técnicas existentes no passado e coloca novos problemas relacionados com a avidez de lucros das grandes corporações farmacêuticas. As populações mais ne- 
cessitadas nem sempre podem ser atendidas, em vista das relações mercantis envolvidas na disputa por mercados globalizados. A polêmica vacina contra Aids não escapa a esta lógica perversa, com agravantes representados pelo questionamento das ciências biomédicas básicas, que põem em dúvida a sua viabilidade, e da sociedade organizada, que reclama por um comportamento mais ético por parte da indústria.

Abstract-The history of disease control through vaccination is relatively recent, dating back to no more than 200 years. Empirical proposals in their beginning, vaccines got strengthened in late XIX century with the emergence of the Germ Theory, paradigm still dominant in health sciences. The recent developments of biotechnology surpass past difficulties and pose new ones, like the appetite of the large pharmaceutical corporations for profits. The populations in need cannot always be satisfied because of the trade relations involved in the fight for global markets. The controversial Aids vaccine does not escape from such perverse logic, aggravated by the arguments of basic biomedical sciences that cast doubt on its feasibility, and also by organized communities, that claim for a more ethical behavior from the industry.

José da Rocha Carvalbeiro é médico, formado pela Faculdade de Medicina da USP em 1961, professor titular de Medicina Social da Faculdade de Medicina de Ribeirão Preto da USP, colaborador-pleno do IEA-USP e diretor do Instituto de Saúde da Secretaria de Estado da Saúde de São Paulo.

Este trabalho faz parte da reflexão a respeito da factibilidade de ensaios de vacinas antiHIV/Aids no Brasil no contexto do Projeto Bela Vista (Instituto de Saúde - SES/SP). Financiamento: OMS, Onusida; Ministério da Saúde; CNPq; Fapesp.

$\mathrm{O}$ autor agradece os comentários críticos à versão preliminar do trabalho, feitos por Dirceu Bartolomeu Greco e Antonio Carlos Toledo Jr., de Belo Horizonte, e por José Ruben de Alcântara Bonfim, de São Paulo. 